\title{
Multiplex PCR for the Simultaneous Identification and Detection of Meloidogyne incognita, M. enterolobii, and M. javanica Using DNA Extracted Directly from Individual Galls
}

\author{
M. X. Hu, K. Zhuo, and J. L. Liao
}

Laboratory of Plant Nematology, South China Agricultural University, Guangzhou, China. Accepted for publication 27 June 2011.

\begin{abstract}
Hu, M. X., Zhuo, K., and Liao, J. L. 2011. Multiplex PCR for the simultaneous identification and detection of Meloidogyne incognita, $M$. enterolobii, and $M$. javanica using DNA extracted directly from individual galls. Phytopathology 101:1270-1277.

Meloidogyne incognita, $M$. enterolobii, and $M$. javanica are the most widespread species of root-knot nematodes in South China, affecting many economically important crops, ornamental plants, and fruit trees. In this study, one pair of Meloidogyne universal primers was designed and three pairs of species-specific primers were employed successfully to rapidly detect and identify $M$. incognita, $M$. enterolobii, and $M$. javanica by multiplex polymerase chain reaction (PCR) using DNA extracted from individual galls. Multiplex PCR from all $M$. incognita, $M$. enterolobii, and $M$. javanica isolates generated two fragments of $\approx 500$ and $1,000,500$

internal positive control fragment of rDNA 28S D2/D3 resulting from the use of the universal primers. Other Meloidogyne spp. included in this study generated only one fragment of $\approx 500 \mathrm{bp}$ in size. Using this approach, $M$. incognita, $M$. enterolobii, and $M$. javanica were identified and detected using DNA extracted directly from individual galls containing the Meloidogyne spp. at various stages of their life cycle. Moreover, the percentage of positive PCR amplification increased with nematode development and detection was usually easy after the late stage of the second-stage juvenile. The protocol was applied to galls from naturally infested roots and the results were found to be fast, sensitive, robust, and accurate. This present study is the first to provide a definitive diagnostic tool for $M$. incognita, $M$. enterolobii, and $M$. javanica using DNA extracted directly from individual galls using a one-step multiplex PCR technique.
\end{abstract} and 200, and 500 and $700 \mathrm{bp}$, respectively. The 500-bp fragment is the
Root-knot nematodes are widely distributed in South China, a region containing tropical and subtropical areas, and these parasites cause substantial losses to agricultural crops. Previously, the nematodes Meloidogyne incognita, $M$. javanica, and $M$. arenaria were considered to be of major economic importance in this region $(11,24,30,32)$. More recently, greater attention has focused on $M$. enterolobii, a species originally described from the Hainan Province in China (31). M. enterolobii has been found to damage $\approx 20$ plant species in South China, including members of six plant families: Fabaceae, Cucurbitaceae, Solanaceae, Myrtaceae, Annonaceae, and Marantaceae (34). Furthermore, this species can reproduce on root-knot nematode-resistant tomato, pepper, and tobacco cultivars that carry the $M i$ gene $(13,33)$. It has been suggested that $M$. enterolobii is a senior synonym of $M$. mayaguensis $(20,30)$, which is important due to its wide geographical distribution, host range, and ability to overcome the resistance of tomato and pepper genotypes carrying the $\mathrm{Mi}-1, \mathrm{~N}$, and Tabasco genes $(7,10)$. During the last 3 years, $\approx 1,000$ samples were collected in South China by our laboratory, and $M$. incognita, $M$. enterolobii, and $M$. javanica were the most common species, occurring in 62,18 , and $11 \%$ of the samples, respectively (unpublished data).

It is difficult to differentiate these Meloidogyne spp. from each other based on the morphology of their perineal patterns alone, because there is considerable morphological similarity between

Corresponding author: J. L. Liao; E-mail address: jlliao@scau.edu.cn

First and second authors contributed equally to this paper.

doi:10.1094/PHYTO-04-11-0095

(C) 2011 The American Phytopathological Society the species and there is also high intraspecies variation. The perineal pattern of $M$. enterolobii is rounded with high dorsal arches, which is very similar to that seen in $M$. incognita $(13,33)$. Identification of Meloidogyne spp. using isozyme phenotyping is useful but this technique is limited to females. DNA analyses have been widely used for the identification of major Meloidogyne spp., including $M$. incognita, $M$. javanica, and $M$. enterolobii (=M. mayaguensis). For examples, $M$. incognita, $M$. javanica, $M$. hapla, $M$. arenaria, and $M$. chitwoodi can be discriminated using COII polymerase chain reaction (PCR) restriction fragment length polymorphism (RFLP) (17); $M$. incognita, M. javanica and $M$. arenaria can be identified by PCR using sequence-characterized amplified region (SCAR) primers $(15,36)$; and $M$. incognita or $M$. javanica can be identified by real-time PCR $(3,29)$. More recently, numerous molecular techniques have been developed for identifying $M$. enterolobii, including analyses based on mitochondrial DNA (mtDNA) $(5,6,28,30,34)$ and ribosomal DNA (rDNA) intergenic regions (IGS) $(1,4)$, PCR amplifications using species-specific primers derived from IGS2 (14) and satellite DNA families (20), and random amplification of polymorphic DNA (RAPD)-PCR (27). These studies have demonstrated the effectiveness of identifying and differentiating Meloidogyne spp. using molecular techniques. However, a multiplex PCR method for the simultaneous identification of $M$. incognita, $M$. enterolobii, and $M$. javanica has not been reported previously.

For some plant nematodes, such as Nacobbus spp. (2) and Bursaphelenchus xylophilus (25), infected plant tissue has been used directly for the extraction of DNA for analysis of plant nematode species. More recently, $M$. incognita was detected by PCR in planta using template DNA derived from banana roots before gall formation (21). Approaches for extracting DNA directly from 
galls infected with Meloidogyne spp. are available but methodologies for detecting Meloidogyne spp. from such samples have yet to be reported (16).

In the present study, DNA from individual galls of tomato, cucumber, and water spinach, each known to contain Meloidogyne spp. at different stages of the nematode life cycle, were extracted to detect and identify $M$. incognita, $M$. enterolobii, and $M$. javanica via a one-step multiplex PCR. The aims of this present study were to (i) explore methods for extracting DNA from individual Meloidogyne-containing galls; (ii) test and develop primers to amplify Meloidogyne DNA from individual galls during different stages of the Meloidogyne life cycle for the detection and identification of $M$. incognita, $M$. enterolobii, and $M$. javanica by one-step multiplex PCR; and (iii) apply this new methodology to plant samples from the field.

\section{MATERIALS AND METHODS}

Nematode isolates and DNA extraction. All the nematodes listed in Table 1 were collected and morphologically identified in our laboratory. Meloidogyne spp. were confirmed by isozyme and molecular data, while other plant nematodes were confirmed using only molecular data. Meloidogyne populations were purified from single egg masses and reared on the appropriate plant hosts, except that M. hapla. M. incognita, M. javanica, M. enterolobii, and $M$. arenaria isolates were reared on tomato while $M$. graminicola and M. graminis were reared on rice and bermudagrass, respectively. DNA was extracted from individual nematodes (12) and this was used immediately for PCR or stored at $-80^{\circ} \mathrm{C}$ until later use.

Primer design and selection. Using alignments obtained from GenBank, the Meloidogyne spp.-specific forward primer was designed based on a region conserved across Meloidogyne nematodes in the 28S rRNA D2D3 expansion domain (MF 5'GGGGATGTTTGAGGCAGATTTG-3'; inside the D2 region), while the universal reverse primer was designed based on a region conserved across plant nematodes in the 28S rRNA D2D3 expansion domain (MR 5'-AACCGCTTCGGACTTCCACCAG3'; inside the D3 region). M. incognita-specific primers (Mi-F 5'GTGAGGATTCAGCTCCCCAG-3' and Mi-R 5'-ACGAGGAA CATACTTCTCCGTCC-3') and $M$. javanica-specific primers (Fjav 5'-GGTGCGCGATTGAACTGAGC-3' and Rjav 5'-CAG GCCCTTCAGTGGAACTATAC-3') that amplify SCAR markers were described by Meng et al. (15) and Zijlstra et al. (36), respectively. rDNA-IGS2 internal primers (Me-F 5'-AACTTTTG TGAAAGTGCCGCTG-3' and Me-R 5'-TCAGTTCAGGCAGG ATCAACC-3') were described by Long et al. (14) to amplify a specific sequence from $M$. enterolobii.

The Basic Local Alignment Search Tool (BLAST) (http:// www.ncbi.nlm.nih.gov/blast) was first used to examine the overall specificity of the primer pairs. Subsequently, these primer sets were tested separately in a PCR prior to multiplex analysis using DNA template from nematodes listed in Table 1. PCR amplification using the Fjav/Rjav primers was performed as described by Zijlstra et al. (36). PCRs with the Me-F/Me-R and the SCAR MiF/Mi-R primers were conducted according to the descriptions of Long et al. (14) and Meng et al. (15), respectively, with the following minor modifications: $94^{\circ} \mathrm{C}$ for $4 \mathrm{~min} ; 35$ cycles of $94^{\circ} \mathrm{C}$ for $30 \mathrm{~s}, 64^{\circ} \mathrm{C}$ for $30 \mathrm{~s}$, and $68^{\circ} \mathrm{C}$ for $1 \mathrm{~min}$; and a final $10-\mathrm{min}$ incubation at $72^{\circ} \mathrm{C}$. PCR using the new MF/MR primers were performed in a $25-\mu$ reaction volume comprising $1 \mu$ of template DNA from an individual nematode, $0.2 \mu \mathrm{M}$ each primer, $2 \times$ buffer, $0.4 \mathrm{mM}$ each dNTP, and $0.5 \mathrm{U}$ of KOD FX polymerase (Toyobo, Shanghai, China). PCR amplifications were performed in a thermocycler (TaKaRa TP600; Shiga, Japan) using the following parameters: $94^{\circ} \mathrm{C}$ for $2 \mathrm{~min} ; 35$ cycles of $94^{\circ} \mathrm{C}$ for

TABLE 1. Meloidogyne spp. and other nematodes used to evaluate the species-specific primers used for multiplex polymerase chain reaction

\begin{tabular}{|c|c|c|c|}
\hline Species & Isolate & Host & Geographical location \\
\hline Meloidogyne incognita & $\mathrm{GNq}$ & Eggplant & Guangxi, China \\
\hline M. incognita & $\mathrm{ZCd}$ & White gourd & Guangdong, China \\
\hline M. incognita & HZ1 & Tomato & Henan, China \\
\hline M. incognita & GLs & Towel gourd & Guangdong, China \\
\hline M. incognita & JS2 & Unknown & Jiangsu, China \\
\hline M. incognita & SSs & Towel gourd & Shandong, China \\
\hline M. javanica & YZy1 & Tobacco & Yunnan, China \\
\hline M. javanica & GNs & Towel gourd & Guangxi, China \\
\hline M. javanica & $\mathrm{ZCf}$ & Tomato & Guangdong, China \\
\hline M. javanica & GNk & Towel gourd & Guangxi, China \\
\hline M. javanica & $\mathrm{SMj}$ & Unknown & Guangdong, China \\
\hline M. javanica & $\mathrm{ZH} 8$ & Peanut & Henan, China \\
\hline M. enterolobii & PY1 & Pepper & Guangdong, China \\
\hline M. enterolobii & $\mathrm{HYz}$ & Arrowroot & Hainan, China \\
\hline M. enterolobii & $\mathrm{GNj}$ & Chrysanthemum & Guangxi, China \\
\hline M. enterolobii & $\mathrm{GNc}$ & Crimson bottle brush & Guangdong, China \\
\hline M. enterolobii & PYk & Bitter gourd & Guangdong, China \\
\hline M. enterolobii & $\mathrm{HNh}$ & Black pepper & Hainan, China \\
\hline M. arenaria & YZy2 & Tobacco & Yunnan, China \\
\hline M. arenaria & HK1 & Palm & Hongkong, China \\
\hline M. hapla & MH1 & Tomato & Liaoning, China \\
\hline M. hapla & HB2 & Peanut & Hebei, China \\
\hline M. graminicola & $\mathrm{ZCs}$ & Rice & Hainan, China \\
\hline M. graminis & YJg & Bermudagrass & Guangdong, China \\
\hline Ditylenchus destructor & $\mathrm{D}$ & Sweet potato & Shandong, China \\
\hline Radopholus similis & Rs & Anthurium & Guangdong, China \\
\hline Pratylenchus zeae & $\mathrm{Pz}$ & Sugarcane & Guangdong, China \\
\hline Pratylenchus coffeae & $\mathrm{Pc}$ & Banana & Guangdong, China \\
\hline Heterodera glycines & $\mathrm{SCN}$ & Soybean & Shenyang, China \\
\hline Tylenchulus semipenetrans & $\mathrm{T}$ & Litchi & Guangdong, China \\
\hline Hirschmanniella oryzae & Hir & Rice & Guangdong, China \\
\hline Rotylenchulus reniformis & $\mathrm{Rr}$ & Cucumber & Anhui, China \\
\hline Aphelenchoides sp. & Apo & Cucumber & Guangdong, China \\
\hline Aphelenchus sp. & Aps & Cucumber & Guangdong, China \\
\hline Cephalobus sp. & Cep & $\ldots$ & Guangdong, China \\
\hline
\end{tabular}


$30 \mathrm{~s}, 64^{\circ} \mathrm{C}$ for $30 \mathrm{~s}$, and $68^{\circ} \mathrm{C}$ for $1 \mathrm{~min}$; and a final $5 \mathrm{~min}$ incubation at $72^{\circ} \mathrm{C}$.

PCR products $(5 \mu \mathrm{l})$ were separated on standard $2 \%$ agarose gels stained with Goldview (EB substation; Toyobo). A DS2000 DNA ladder (Dongsheng Biotech, Shanghai, China) was used to determine the molecular sizes of the bands. Band patterns were photographed under UV light using the Alphalmager (Alpha Innotech). All primers were synthesized by Invitrogen Biotech (Shanghai, China).

Multiplex PCR. The multiplex PCR was optimized by varying the reaction components and cycling conditions. The annealing temperature was increased from 58 to $66^{\circ} \mathrm{C}$ by single incremental temperature units. At the selected annealing temperature, the amplifications were carried out for different extension times (30, $60,90$, and $120 \mathrm{~s})$ and at different concentrations of primers $(0.02$ to $0.4 \mu \mathrm{M})$ and dNTPs $(0.02,0.06,0.1,0.2,0.3,0.4$, and $0.5 \mathrm{mM})$. Finally, optimal PCR amplifications were performed in $25-\mu 1$ reaction volumes comprising $1 \mu \mathrm{l}$ of template DNA from an individual nematode or DNA mixture (DNA from different Meloidogyne spp. were mixed in a ratios of $1: 1) ; 0.1 \mu \mathrm{M}$ MF and MR primers; $0.12 \mu \mathrm{M}$ Me-F and Me-R primers; $0.16 \mu \mathrm{M}$ Mi-F, Mi-R, Fjav, and Rjav primers; $2 \times$ buffer; $0.4 \mathrm{mM}$ each dNTP; and $0.5 \mathrm{U}$ of KOD FX polymerase. Multiplex-PCR amplification parameters were as follows: $94^{\circ} \mathrm{C}$ for $2 \mathrm{~min} ; 35$ cycles of $94^{\circ} \mathrm{C}$ for $30 \mathrm{~s}, 64^{\circ} \mathrm{C}$ for $30 \mathrm{~s}$, and $68^{\circ} \mathrm{C}$ for $1 \mathrm{~min}$; and a final 5-min incubation at $72^{\circ} \mathrm{C}$.

DNA extraction from individual galls infected with Meloidogyne spp. and assessments of efficiency. Tomato plants infected with Meloidogyne spp. were collected from fields. The roots were flushed with water to remove soil and then washed with a $0.52 \%$ $\mathrm{NaClO}$ soap for $10 \mathrm{~min}$. Individual root knots were obtained following three to five washes. DNA extraction was performed using the following four methods.

Method 1: DNA was extracted using a method modified from Stanton et al. (23). Individual galls were placed into $1.5-\mathrm{ml}$ centrifuge tubes with $45 \mu \mathrm{l}$ of $50 \mathrm{mM} \mathrm{NaOH}$ and ground with a selfmade glass muller. Tubes were incubated at $95^{\circ} \mathrm{C}$ for $10 \mathrm{~min}$. Following this incubation, $5 \mu \mathrm{l}$ of $1 \mathrm{M}$ Tris- $\mathrm{HCl}(\mathrm{pH}$ 8.0) was added to each tube and then mixed thoroughly. The tubes were subsequently centrifuged at $10,000 \times g$ for $1 \mathrm{~min}$, and then the supernatant was transferred to PCR tubes for PCR amplification or stored at $-20^{\circ} \mathrm{C}$ until later use.

Method 2: DNA was extracted following the protocol of Thomson and Henry, with minor modifications (26). Individual galls were placed in $1.5-\mathrm{ml}$ centrifuge tubes with $50 \mu \mathrm{l}$ of buffer $\mathrm{A}$ (100 mM Tris- $\mathrm{HCl}$ [pH 9.5], $1 \mathrm{M} \mathrm{KCl}$, and $10 \mathrm{mM}$ EDTA) and ground with a self-made glass muller. Tubes were incubated at $95^{\circ} \mathrm{C}$ for $10 \mathrm{~min}$. Subsequently, the samples were centrifuged at $10,000 \times g$ for $1 \mathrm{~min}$, and then the supernatant was transferred to PCR tubes for PCR amplification or stored at $-20^{\circ} \mathrm{C}$ until later use.

Method 3: DNA was extracted using a method modified from Iwahori et al. (9). Individual root knots were placed in PCR tubes and ground under liquid nitrogen. Then, to each tube was added $700 \mu \mathrm{l}$ of lysis buffer (50 mM Tris- $\mathrm{HCl}$ [pH 7.5], $50 \mathrm{mM} \mathrm{NaCl}$, 5 mM EDTA [pH 8.0], 0.5\% sodium dodecyl sulfate, and proteinase $\mathrm{K}$ at $20 \mathrm{mg} / \mathrm{ml}$ ) (TaKaRa). The tubes were incubated for $4 \mathrm{~h}$ at $50^{\circ} \mathrm{C}$ with occasional mixings. An equal volume $(700 \mu \mathrm{l})$ of phenol was added and the tubes were centrifuged at $10,000 \times g$ for $10 \mathrm{~min}$. Then, the supernatants were transferred to new tubes and an equal volume of chloroform:isoamyl alcohol (24:1) was added. The tubes were subsequently centrifuged at $10,000 \times g$ for $10 \mathrm{~min}$, and then the supernatants were transferred to new tubes. The DNA solutions received $1 / 10$ volume of $3 \mathrm{M}$ sodium acetate (pH 5.2) and 2.5 volumes of $99.5 \%$ ethanol $\left(-20^{\circ} \mathrm{C}\right)$ and were then kept at $-20^{\circ} \mathrm{C}$ for $2 \mathrm{~h}$, before centrifugation at $10,000 \times g$ for $10 \mathrm{~min}$. The precipitated DNA pellet was washed twice with $70 \%$ ethanol $\left(-20^{\circ} \mathrm{C}\right)$, then dried and resuspended in $50 \mu \mathrm{l}$ of
Tris-EDTA (TE) buffer $(10 \mathrm{mM}$ Tris- $\mathrm{HCl}$ and $1 \mathrm{mM}$ EDTA [pH 8.0]).

Method 4: DNA was extracted using the 3S Spin Genomic DNA Miniprep Kit v3.0 (Shenergy Biocolor, Shanghai, China) according to the manufacturer's protocol after grinding individual root knots in a $1.5-\mathrm{ml}$ sterile tube under liquid nitrogen. Finally, $50 \mu \mathrm{l}$ of TE buffer was used to elute the DNA.

The efficiency of DNA isolation from individual galls using the four methods described above was assessed by performing the same multiplex-PCR as above, except that $4 \mu \mathrm{l}$ of template DNA from individual galls was used and 40 cycles of PCR amplification were performed.

Discrimination of $M$. incognita, $M$. enterolobii, and $M$. javanica in artificially inoculated roots. Twenty-five-day-old tomato (Lycopersicon esculentum), cucumber (Cucumis sativus), and water spinach (Ipomoea aquatica) seedlings were transplanted into pots $15 \mathrm{~cm}$ in diameter containing autoclaved soil and maintained under greenhouse conditions at $25^{\circ} \mathrm{C}$. Two hundred Meloidogyne second-stage juveniles (J2), including six isolates each of $M$. incognita, $M$. enterolobii, and $M$. javanica, were inoculated onto the plant roots. Each host plant species was inoculated with water as a negative control. Nematodes were observed at 5,10,15,20,25, and 30 days after inoculation using the method of Feng (8) and photographed with a digital camera (Olympus CX21). DNA was extracted from individual galls at 5, $10,15,20,25$, and 30 days postinoculation and one section of healthy root (to serve as the negative control) using method 1 described above. Ten replicates of individual galls from each sample were selected for DNA extraction. The PCRs were the same as those employed for the multiplex PCR above, except that 40 cycles and $4 \mu \mathrm{l}$ of template DNA were used. Finally, the percentage of positive PCR amplifications was calculated according to the following ratio: (numbers of galls showing positive $\mathrm{PCR} /$ numbers of total galls tested) $\times 100 \%$.

Validation of Meloidogyne spp. identification in naturally infested roots. Thirty naturally infested root samples from eight different host plant species (tomato, eggplant, pepper, cucumber, bitter gourd, white gourd, pumpkin, and lettuce) were collected from Guangdong, Guangxi, Hainan, and Yunnan, China. Five appropriate galls of each sample were selected for the extraction of DNA and multiplex-PCR was performed as described above. To validate the protocol, the Meloidogyne spp. in each sample were identified based on their morphology and isozyme phenotype.

Sequencing. To verify whether the PCR products obtained from the primers were the expected sequences, the differently sized bands resulting from the PCRs were separately excised and purified using a universal DNA gel purification kit (Tiangen Biotech, Beijing). The fragments were cloned individually into the pMD 18-T vector and sequenced. Sequencing reactions were run on an ABI3730 Stretch DNA sequencing system (Applied Biosystems, Foster City, CA). Mega 4 or BLAST was used to conduct homology comparisons on the sequences generated.

\section{RESULTS}

PCR primer specificity. BLAST analysis of the primer sequences indicated that the Meloidogyne forward-specific primer MF exhibited $100 \%$ matches with $M$. hispanica (GQ375158 and EU443606 to EU443608), M. thailandica (EU364890), M. arenaria (AF435803, EU364889, U42339, and U42342), M. paranaensis (AF435798 to AF435800), M. konaensis (AF435797), $M$. incognita (AF43579), M. silvestris (EU570214), M. graminicola (HQ420904, HQ420905, and AF435793), M. fallax (FN429017), M. dunensis (EF612712), M. exigua (AF435795, AF435796, and AF435804), M. chitwoodi (AF435802), and M. trifoliophila (AF435801) sequences. The universal reverse primer MR exhibited $100 \%$ matches with different groups of nematodes including plant nematodes, freeliving nematodes, and entomopathogenic 
nematodes (accession numbers were omitted). $M$. enterolobiispecific primer pairs $\mathrm{Me}-\mathrm{F} / \mathrm{Me}-\mathrm{R}$ only matched $M$. enterolobii and $M$. mayaguensis ( $=$ M. enterolobii) (GQ395524 to GQ39556 and DQ641506). M. incognita-specific primer pairs Mi-F/Mi-R and $M$. javanica-specific primer pairs Fjav/Rjav showed that there were no sequences exhibiting high matching.

Primer specificity was further examined by PCR using genomic DNA extracted separately from the nematodes listed in Table 1. All Meloidogyne isolates generated one fragment of $\approx 500 \mathrm{bp}$ using the Meloidogyne-universal MF/MR primers, M. incognita generated a fragment of $\approx 1,000 \mathrm{bp}$ using the Mi-F/Mi-R primers, $M$. javanica generated a fragment of $\approx 700 \mathrm{bp}$ using the Fjav/Rjav primers, and $M$. enterolobii gave a fragment of $\approx 200 \mathrm{bp}$ using the Me-F/Me-R primers. No band was observed in the other PCRs. The specificity of all PCR products was confirmed by DNA sequencing. Sequencing results indicated that the $\approx 500$-bp fragment was, in fact, 478 bp for M. enterolobii, M. incognita, M. javanica, and $M$. arenaria; 481 bp for $M$. hapla; and $485 \mathrm{bp}$ for $M$. graminicola and $M$. graminis. The $\approx 1,000$-bp fragment was 955 bp for $M$. incognita, while the 200-bp fragment was $236 \mathrm{bp}$ for $M$. enterolobii and the 700-bp fragment was 657 or $660 \mathrm{bp}$ for $M$. javanica. These sequences have been deposited in GenBank with sequence accession numbers JN005834 to JN005875.

Multiplex PCR. The multiplex-PCR conditions were optimized as described above. Optimal multiplex PCR revealed that each $M$. incognita isolate generated two fragments of $\approx 500$ and $1,000 \mathrm{bp}$, each $M$. javanica isolate gave fragments of $\approx 500$ and $700 \mathrm{bp}$, and each $M$. enterolobii isolate generated fragments of $\approx 500$ and $200 \mathrm{bp}$. All other Meloidogyne spp. gave only one fragment of $\approx 500 \mathrm{bp}$ in length. The mixture of $M$. incognita and $M$. javanica produced three fragments of $\approx 500,700$, and $1,000 \mathrm{bp}$. The mixture of $M$. incognita and M. enterolobii pro- duced three fragments of $\approx 200,500$, and $1,000 \mathrm{bp}$. The mixture of $M$. enterolobii and $M$. javanica produced three fragments of $\approx 200,500$, and $700 \mathrm{bp}$. Finally, the mixture of $M$. incognita, $M$. enterolobii, and $M$. javanica produced four fragments of $\approx 200$, 500,700 , and 1,000 bp. No bands were observed from the nonMeloidogyne spp. tested (Fig. 1).

DNA extraction efficiency applying different methods. No bands were observed with template DNA extracted from individual galls when method 2 was used, whereas the other three methods yielded DNA template sufficient for PCR amplifications with the four pairs of primer. Indeed, bands were all clearly visible using template DNA extracted with these three methods (Fig. 2).

Discrimination of $M$. incognita, M. enterolobii, and $M$. javanica in artificially inoculated roots. Five days after inoculation, small galls were visible with the naked eye, and the nematodes were early parasitic J2s. Root galls enlarged quickly and turned from spindle shaped to round in appearance, while the nematode developed from vermiform to sausage-shaped and eventually to pear-shaped, undergoing late J2 (10 days), third- or fourth-stage juvenile (15 days), and female stages (20 days). At 25 days, eggs were produced, and these were apparent after 30 days.

DNA from individual cucumber galls at different stages of the Meloidogyne life cycle was amplified successfully using the four pairs of primers MF/MR, Mi-F/Mi-R, Fjav/Rjav, and Me-F/Me-R. The DNA amplification banding patterns achieved from extracting the DNA directly from individual galls (Fig. 3A) were consistent with those obtained from genomic DNA purified from Meloidogyne isolates. Thus, two fragment bands of $\approx 500$ and $1,000 \mathrm{bp}$ were detected for the $M$. incognita isolates, fragments of 500 and $700 \mathrm{bp}$ were observed for the M. javanica isolates, and fragments of 500 and $200 \mathrm{bp}$ were obtained for M. enterolobii. The multi-

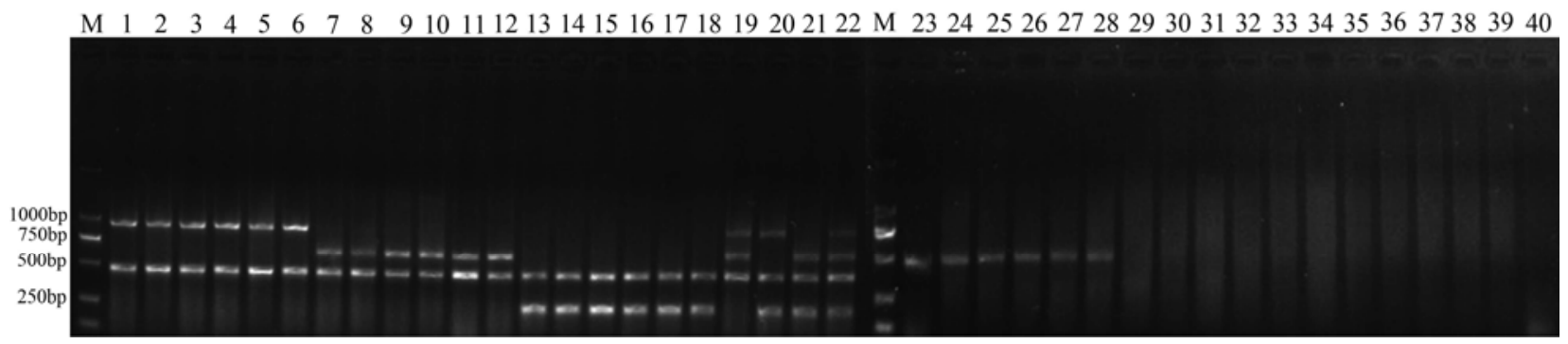

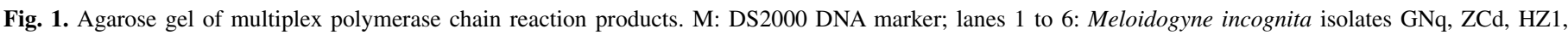

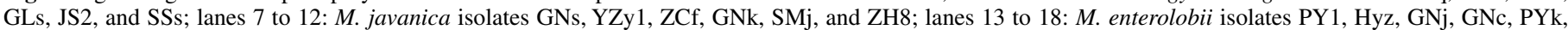

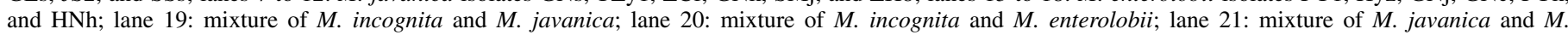

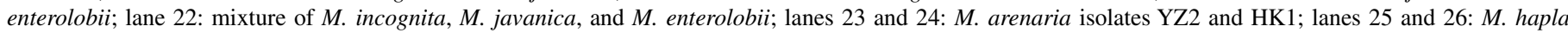

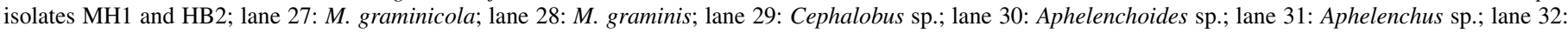

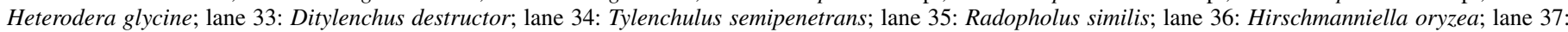
Pratylenchus coffea; lane 38: Pratylenchus zeae; lane 39: Rotylenchulus reniformis; lane 40: water control.

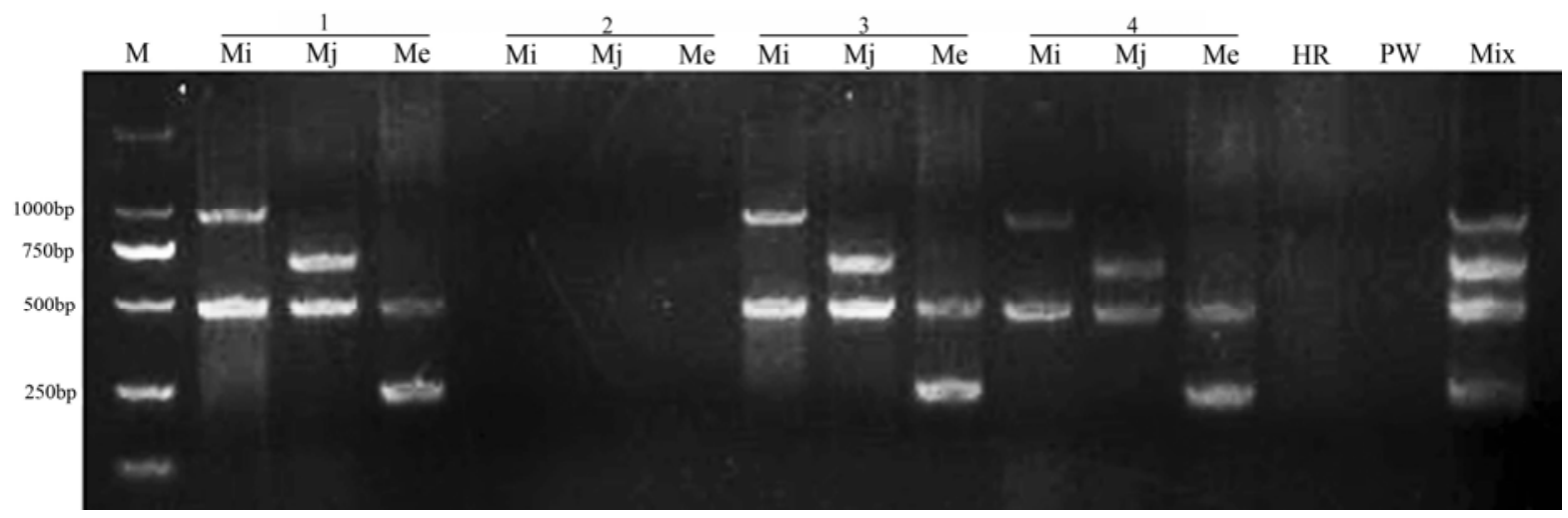

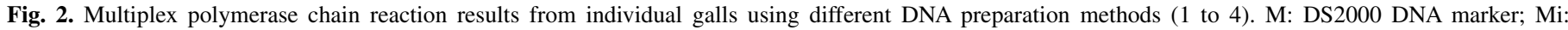

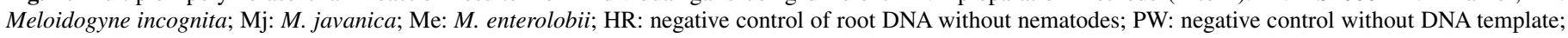
Mix: positive control with a mixture of bulk DNA from $M$. incognita, $M$. javanica, and $M$. enterolobii. 
plex PCR test results were the same for individual galls taken from tomato and water spinach plants, except that, at 5 days after inoculation with $M$. incognita, no fragments were observed from water spinach galls (Fig. 3B and C). The percentage of positive PCR amplifications using DNA extracted directly from individual galls found on the three plant species during any stage of the Meloidogyne sp. life cycle are shown in Table 2. Of the galls containing $M$. enterolobii isolates, $100 \%$ generated two fragments at all stages of the nematode life cycle in all three of the crop plants. For the $M$. javanica isolates, at 10 to 30 days post- inoculation of cucumber and tomato, $100 \%$ of the galls showed positive PCR amplification while, in water spinach, $100 \%$ of the galls gave successful amplifications at 15 to 30 days after inoculation. For the $M$. incognita isolates, $100 \%$ of the galls gave positive PCR amplification at 20 to 30 days postinoculation.

Detection of Meloidogyne spp. in naturally infested roots. The multiplex PCR was evaluated for its ability to detect and identify Meloidogyne spp. in 30 root samples from the field. In 20 cases, all five individual galls from each sample exhibited positive PCR amplifications; in six of the samples, four individual galls

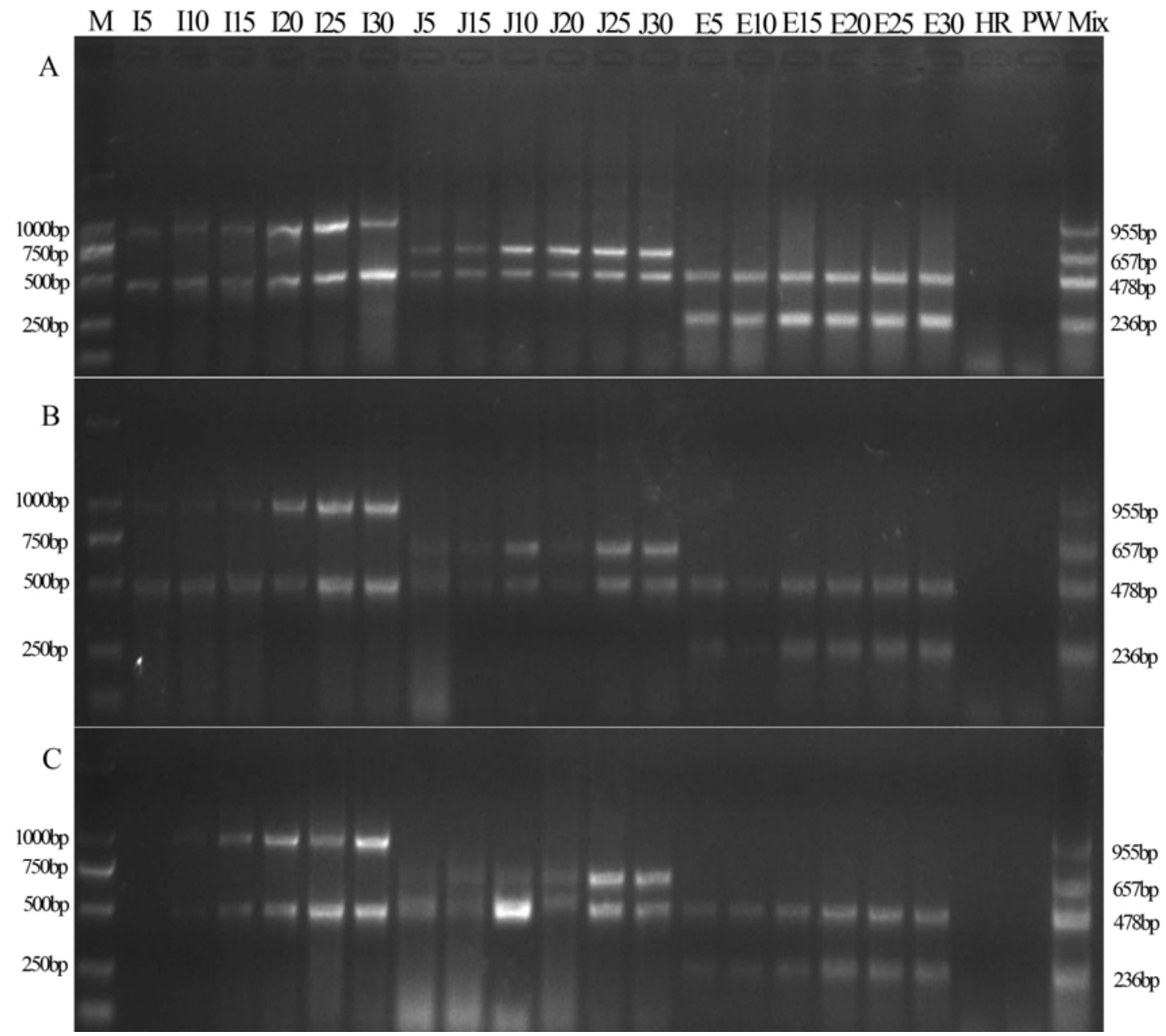

Fig. 3. Agarose gel of multiplex polymerase chain reaction products using DNA extracted from individual galls from A, cucumber; B, tomato; and $\mathbf{C}$, water spinach inoculated with different Meloidogyne spp. M: DS2000 DNA marker; I5, I10, I15, I20, I25, and I30 indicate galls from plants at 5, 10, 15, 20, 25, and 30 days after inoculation with Meloidogyne incognita, respectively; J5, J10, J15, J20, J25, and J30 indicate galls from plants at 5, 10, 15, 20, 25, and 30 days after inoculation with M. javanica, respectively; E5, E10, E15, E20, E25, and E30 indicate galls from plants at 5, 10, 15, 20, 25, and 30 days after inoculation with M. enterolobii, respectively; HR: negative control of healthy roots without nematodes; PW: negative control with no DNA added; Mix: positive control with a mixture of bulk DNA from M. incognita, M. javanica, and M. enterolobii.

TABLE 2. Percentage of positive polymerase chain reaction (PCR) amplifications using DNA extracted directly from individual galls at different days after inoculation (DAI) of the Meloidogyne spp.

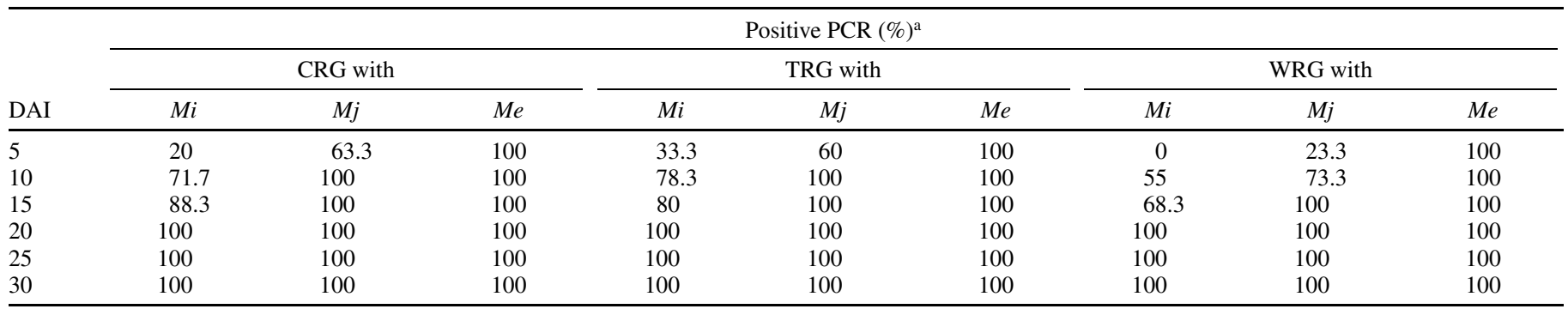

a Percentage of positive PCR $=$ (numbers of galls showing positive PCR/numbers of total galls tested) $\times 100 \%$. CRG = root gall of cucumber, TRG $=$ root gall of tomato, $\mathrm{WRG}=$ root gall of water spinach, $M i=M$. incognita, $M j=M$. javanica, and $M e=M$. enterolobii. 
gave positive PCR amplifications; while in the remaining four samples, three individual galls gave positive PCR amplifications (Table 3). Overall, $90.7 \%$ of the galls showed positive PCR amplifications, and all 30 samples contained a root-knot nematode species or mixture of species. Based on the multiplex-PCR amplification patterns, 18 samples were identified as containing $M$. incognita, five samples contained $M$. javanica, four samples contained $M$. enterolobii, one sample had mixed populations of $M$. incognita and $M$. javanica, and another sample had mixed populations of $M$. incognita and $M$. enterolobii. All these results were confirmed using standard morphological and isozyme methodologies, except for one tomato sample (from Shenzhen, Guangdong). In this sample, the PCRs from all five galls selected gave fragments of $\approx 500$ and $700 \mathrm{bp}$ (indicating the presence of $M$. javanica) but morphological observations and isozyme assessments indicated that there were, in fact, mixed populations of $M$. incognita and $M$. javanica. Finally, the remaining sample (a lettuce sample from Zengcheng, Guangdong) gave one fragment of $\approx 500 \mathrm{bp}$ from all five galls, and the infestation was identified as $M$. arenaria based on morphology and isozyme assay.

\section{DISCUSSION}

For multiplex PCR using more than one primer set, it is important to determine the specificity and sensitivity of the primers and optimize the PCR reaction conditions (22). In this study, serial PCRs were tried using different annealing temperatures, primer concentration ratios, and primer pairs, and this eventually led to the determination of the best program and primers for the multiplex PCR. In the multiplex PCR, a fragment of $\approx 500$ bp was amplified from all galls containing Meloidogyne spp. using the MF/MR primers as was expected. This also confirmed the presence of template nematode DNA that had been extracted from individual galls. PCRs using the specific primer pairs Mi-F/Mi-R, Fjav/Rjav, and Me-F/Me-R produced DNA fragments of 955, 657 or 660, and $236 \mathrm{bp}$, respectively, which corresponded to the galls containing $M$. incognita, $M$. javanica, and $M$. enterolobii, respectively. Using these specific primer pairs, no fragments were generated from galls containing any other Meloidogyne spp. These results indicated the absence of mutual interference in the PCR amplification, that the primer pairs were species-specific and sensitive, and that the PCR conditions were ideal for the rapid detection and discrimination of $M$. incognita, $M$. javanica, and $M$. enterolobii from individual plant galls. This approach requires only one PCR reaction using DNA extracted directly from an individual gall, meaning that it is simple, rapid, and reliable.

$M$. incognita, $M$. enterolobii, and $M$. javanica have become the most important root-knot nematode species in South China (unpublished data). In this study, multiplex PCR using speciesspecific primers performed on DNA extracted from individual root-knot galls was employed to rapidly detect and identify these three species of nematodes. Though there are many molecular techniques for detecting these Meloidogyne spp. (1,3-6,15,17, 20,27-30,36), none of these other methods identify and discriminate these three important species simultaneously by multiplex PCR, a method that has been used to differentiate other Meloidogyne spp. (19,35). Moreover, these techniques were developed using DNA extracted from nematode specimens isolated from plant tissues or soils but not using DNA extracted directly from individual galls. Direct molecular detection of plant-parasitic

TABLE 3. Identification results of Meloidogyne spp. by multiplex polymerase chain reaction (PCR) using DNA extracted from individual galls from naturally infested root samples ${ }^{\mathrm{a}}$

\begin{tabular}{|c|c|c|c|c|c|c|c|}
\hline \multirow[b]{2}{*}{ Geographical origin } & \multirow[b]{2}{*}{ Host } & \multicolumn{5}{|c|}{ Single gall amplification pattern ${ }^{\mathrm{b}}$} & \multirow[b]{2}{*}{ Confirmation $^{\mathrm{c}}$} \\
\hline & & Gall 1 & Gall 2 & Gall 3 & Gall 4 & Gall 5 & \\
\hline Panyu, Guangdong, China & Eggplant & 3 & 3 & 3 & 3 & 3 & $M e$ \\
\hline Panyu, Guangdong, China & Pepper & 3 & 3 & 3 & 3 & 3 & $M e$ \\
\hline Nama, Guangxi, China & Cucumber & 1 & 1 & 1 & 1 & 1 & $M i$ \\
\hline Nama, Guangxi, China & Bitter gourd & 1 & 1 & 2 & 2 & 1 & $M i / M j$ \\
\hline Nama, Guangxi, China & Eggplant & 1 & 1 & 0 & 1 & 1 & $M i$ \\
\hline Zengcheng, Guangdong, China & Lettuce & 4 & 4 & 4 & 4 & 4 & $M a$ \\
\hline Zengcheng, Guangdong, China & White gourd & 1 & 1 & 1 & 1 & 1 & $M i$ \\
\hline Guangzhou, Guangdong, China & Tomato & 1 & 1 & 1 & 1 & 1 & $M i$ \\
\hline Guangzhou, Guangdong, China & Bitter gourd & 1 & 1 & 1 & 1 & 1 & $M i$ \\
\hline Guangzhou, Guangdong, China & Cucumber & 1 & 1 & 1 & 1 & 1 & $M i$ \\
\hline Guangzhou, Guangdong, China & Pepper & 0 & 1 & 1 & 1 & 1 & $M i$ \\
\hline Shenzhen, Guangdong, China & Cucumber & 1 & 1 & 1 & 1 & 1 & $M i$ \\
\hline Panyu, Guangdong, China & Eggplant & 1 & 0 & 1 & 1 & 0 & $M i$ \\
\hline Panyu, Guangdong, China & Pumpkin & 1 & 1 & 1 & 1 & 1 & $M i$ \\
\hline Panyu, Guangdong, China & White gourd & 1 & 1 & 0 & 1 & 1 & $M i$ \\
\hline Shaoguan, Guangdong, China & Eggplant & 1 & 1 & 1 & 0 & 1 & $M i$ \\
\hline Shaoguan, Guangdong, China & Eggplant & 2 & 0 & 2 & 2 & 2 & $M j$ \\
\hline Shaoguan, Guangdong, China & Pepper & 0 & 2 & 2 & 0 & 2 & $M j$ \\
\hline Shaoguan, Guangdong, China & Bitter gourd & 1 & 1 & 1 & 1 & 1 & $M i$ \\
\hline Shaoguan, Guangdong, China & Pepper & 3 & 3 & 3 & 3 & 3 & $M e$ \\
\hline Yuanmou, Yunnan, China & Pepper & 1 & 1 & 0 & 1 & 0 & $M i$ \\
\hline Yuanmou, Yunnan, China & Tomato & 1 & 1 & 1 & 1 & 1 & $M i$ \\
\hline
\end{tabular}

${ }^{a}$ Results were confirmed by morphology and isozyme phenotypes.

b PCR scale: 0 indicates a single gall giving no fragments, 1 indicates a single gall giving two fragments of $\approx 500$ and 1,000 bp (showing the presence of $M$. incognita), 2 indicates a single gall giving two fragments of $\approx 500$ and $700 \mathrm{bp}$ (showing the presence of $M$. javanica), 3 indicates a single gall giving two fragments of $\approx 500$ and $200 \mathrm{bp}$ (showing the presence of $M$. enterolobii), and 4 indicates a single gall giving one fragment of 500 bp (showing the presence of other Meloidogyne spp. except M. incognita, M. javanica, and M. enterolobii).

${ }^{\mathrm{c}}$ Morphology and isozyme confirmation; $M i=M$. incognita, $M j=M$. javanica, $M e=M$. enterolobii, and $M a=M$. arenaria . 
nematodes using template DNA from plant tissues containing nematodes may be useful for early detection but only a few cases of such an approach have been reported to date. Takeuchi et al. (25) developed a nested PCR-based method to identify the pine wood nematode, B. xylophilus, while Atkins et al. (2) refined a molecular diagnostic approach to detect Nacobbus spp. in soil and potato tubers. Methods for the early detection of Meloidogyne spp. directly from banana roots before gall formation have also been reported (21). However, due to the difficulty in collecting such non-gall roots for diagnosing Meloidogyne spp. infection, in practice, we aimed to diagnose Meloidogyne spp. from individual galls using a molecular approach. A one-step multiplex PCR method was designed and employed successfully to identify and discriminate the three tropical and subtropical nematode species $M$. incognita, $M$. enterolobii, and $M$. javanica from individual nematodes as well as individual galls. This is the first time that such a method has been reported and this present study may help in the design of new tests for the practical detection of other rootknot nematodes. In the present study, we tested the four methods to obtain effective template DNA from individual galls. Expected band sizes were produced using three of these methods; however, fewer reagents and time were required for method 1 compared with methods 3 and 4 and, therefore, method 1 was used throughout to provide DNA easily and quickly from individual galls.

In order to determine which life stages of Meloidogyne spp. could be detected effectively in the gall by PCR, PCRs were performed using template DNA from individual galls at 5, 10, 15, 20, 25, and 30 days after inoculation, which spans the entire life cycle of the nematode. The results indicated that Meloidogyne spp. could be detected at any stage of the life cycle in galls of cucumber and tomato. In water spinach, only at 5 days after inoculation was $M$. incognita not detected. Nevertheless, the percentage of positive PCR amplifications increased with $M$. incognita development and it could be detected more easily after the late stage of the second-stage juvenile. In the present study, $M$. incognita-specific primers were designed based on RAPD fragments from Meng et al. (15). The fragment was sequenced by us and subjected to BLASTN search against the National Center for Biotechnology Information database but no homologous sequences were found. Thus, the sequence may be a low-copy fragment in $M$. incognita and water spinach roots may contain high levels of PCR inhibitors relative to the target DNA at the early stages of $\mathrm{J} 2$, and these reasons could have led to the failure in detecting $M$. incognita in the galls 5 days after inoculation. The Meloidogyne universal primers and $M$. enterolobii-specific primers were designed from multicopy sequences of nuclear ribosomal genes, and $100 \%$ of galls selected gave successful PCR amplifications. Using real-time PCR or changing the primers for those designed against multicopy DNA sequences, such as rDNA or mtDNA, may increase the sensitivity of the assay. Unfortunately, the rDNA of $M$. incognita and $M$. javanica is so homologous that rDNA-based differentiation is impossible $(4,18$, $37)$. In addition, it is also difficult to design primers to discriminate $M$. incognita and $M$. javanica based on mtDNA using a onestep PCR approach because the mtDNA nucleotide sequences of some $M$. incognita populations are highly similar (>99\%) to those of $M$. javanica (unpublished data). In this study, two primer pairs from RAPD fragments were chosen by us for differentiating $M$. incognita and M. javanica simultaneously.

M. incognita, $M$. enterolobii, and $M$. javanica were detected successfully in individual galls using the same PCR conditions at $5,10,15,20,25$, and 30 days after inoculation in artificially inoculated roots of plant species representing divergent plant families, including cucumber (Cucurbitaceae), tomato (Solanaceae), and water spinach (Convulvulaceae). Moreover, the validity of the PCR detection system was confirmed in naturally infested roots of eight plant species. In 29 of the 30 natural samples, PCR detection gave satisfactory results. In only one case did the PCR method fail to identify that galls were infected by mixed populations of $M$. incognita and $M$. javanica; rather, the PCR detected infection by $M$. javanica alone. If more galls in the sample had been collected for PCR detection, perhaps this problem would have been overcome, though more tests are needed to confirm this. In conclusion, this one-step multiplex PCR method can be applied to different crops infected with Meloidogyne spp., which will reduce the time needed to diagnose these nematodes.

\section{ACKNOWLEDGMENTS}

This work was supported by the Special Scientific Research Funds for Commonweal Section of China (grant number 201103018), the Natural Science Foundation of China (grant numbers 30871628 and 31071666), and Planning Project for Science and Technology in Guangdong Province (grant numbers 2007B020709008, 2005B20801013, and 2010A020507001-69). We thank Dr. V. Blok (The James Hutton Institute, U.K.) and Dr. Y. Weimin (North Carolina Department of Agriculture and Consumer Services, U.S.A.) for advice on the article.

\section{LITERATURE CITED}

1. Adam, M. A. M., Phillips, M. S., and Blok, V. C. 2007. Molecular diagnostic key for identification of single juveniles of seven common and economically important species of root-knot nematode (Meloidogyne spp.). Plant Pathol. 56:190-197.

2. Atkins, S. D., Manzanilla-López, R. H., Franco, J., Peteira, B., and Kerry, B. R. 2005. A molecular diagnostic method for detecting Nacobbus in soil and in potato tubers. Nematology 7:193-202.

3. Berry, S. D., Fargette, M., Spaull, V. M., Morand, S., and Cadet, P. 2008. Detection and quantification of root-knot nematode (Meloidogyne javanica), lesion nematode (Pratylenchus zeae) and dagger nematode (Xiphinema elongatum) parasites of sugarcane using real-time PCR. Mol. Cellular Probes 22:168-176.

4. Blok, V. C., Phillips, M. S., McNicol, J. W., and Fargette, M. 1997. Comparison of sequences from the ribosomal DNA intergenic region of Meloidogyne mayaguensis and other major tropical root-knot nematodes. J. Nematol. 29:16-22.

5. Blok, V. C., Wishart, J., Fargette, M., Berthier, K., and Phillips, M. S. 2002. Mitochondrial DNA differences distinguishing Meloidogyne mayaguensis from the major species of tropical root-knot nematodes. Nematology 4:773-781.

6. Brito, J., Powers, T. O., Mullin, P. G., Inserra, R. N., and Dickson, D. W. 2004. Morphological and molecular characterization of Meloidogyne mayaguensis isolates from Florida. J. Nematol. 36:232-240.

7. Brito, J., Stanley, J. D., Kaur, R., Cetintas, R., Di Vito, M., Thies, J. A., and Dickson, D. W. 2007. Effects of the Mi-1,N and Tabasco genes on infection and reproduction of Meloidogyne mayaguensis on tomato and pepper genotypes. J. Nematol. 39:327-332.

8. Feng, Z. X. 2001. Plant Nematology. Chinese Agricultural Publishing, Beijing.

9. Iwahori, H., Tsuda, K., Kanzaki, N., Izui, K., and Futai, K. 1998. PCRRFLP and sequencing analysis of ribosomal DNA of Bursaphelenchus nematodes related to pine wilt disease. Fundam. Appl. Nematol. 21:655666.

10. Kiewnick, S., Dessimoz, M., and Franck, L. 2009. Effects of the Mi-1 and the $N$ root-knot nematode-resistance gene on infection and reproduction of Meloidogyne enterolobii on tomato and pepper cultivars. J. Nematol. 41:134-139.

11. Liao, J. L., Jiang, H., Sun, L. H., Hu, X. Q., Zhang, Z. R., and Wang, X. R. 2003. Identification of species and race of root-knot nematodes on crops in Southern China. J. Huazhong Agric. Univ. 22:544-548.

12. Liao, J. L., Zhang, L. H., and Feng, Z. X. 2001. Reliable identification of Bursaphelenchus xylophilus by rDNA amplification. Nematol. Mediterr. 29:131-135.

13. Liu, H., Long, H., Yan, X. N., and Xu, J. H. 2005. Identification and host range testing of a root-knot nematode infecting guava in Hainan Province. J. Nanjing Agric. Univ. 28:55-59.

14. Long, H., Liu, H., and Xu, J. H. 2006. Development of a PCR diagnostic for the root-knot nematode Meloidogyne enterolobii. Acta Phytopathol. Sin. 36:109-115.

15. Meng, Q. P., Long, H., and Xu, J. H. 2004. PCR assays for rapid and sensitive identification of three major root-knot nematodes, Meloidogyne incognita, M. javanica and M. arenaria. Acta Phytopathol. Sin. 34:204210.

16. Perry, R. N., Moens, M., and Starr, J. L. 2009. Root-Knot Nematodes. CABI Publishing, New York. 
17. Powers, T. O., and Harris, T. S. 1993. A polymerase chain reaction method for identification of five major Meloidogyne species. J. Nematol. 25:1-6.

18. Powers, T. O., Todd, T. G., Burnell, A. M., Murray, P. C. B., Fleming, C. C., Szalanski, A. L., Adams, B. A., and Harris, T. S. 1997. The rDNA internal transcribed spacer region as a taxonomic marker for nematodes. J. Nematol. 29:441-450.

19. Randig, O., Bongiovanni, M., Carneiro, R. M. D. G., and CastagnoneSereno, P. 2002. Genetic diversity of root-knot nematodes from Brazil and development of SCAR markers specific for the coffee-damaging species. Genome 45:862-870.

20. Randig, O., Deau, F., dos Santos, M. F. A., Tigano, M. S., Carneiro, R. M. D. G., and Castagnone-Sereno, P. 2009. A novel species-specific satellite DNA family in the invasive root-knot nematode Meloidogyne mayaguensis and its potential use for diagnostics. Eur. J. Plant Pathol. 125:485-495.

21. Sayed Abdul Rahman, S. A., Mohamed, Z., Othman, R. Y., Swennen, R., Panis, B., De Waele, D., Remy, S., and Carpentier, S. C. 2010. In planta PCR-based detection of early infection of plant-parasitic nematodes in the roots: A step towards the understanding of infection and plant defence. Eur. J. Plant Pathol. 128:343-351.

22. Shen, Z. Y., Qu, W. B., Wang, W., Lu, Y. M., Wu, Y. H., Li, Z. F., Hang, X. Y., Wang, X. L., Zhao, D. S., and Zhang, C. G. 2010. MPprimer: A program for reliable multiplex PCR primer design. BMC Bioinf. 11:143.

23. Stanton, J. M., McNicol, C. G., and Steele, V. 1998. Non-manual lysis of second-stage Meloidogyne juveniles for identification of pure and mixed samples based on the polymerase chain reaction. Australas. Plant Pathol. 27:112-115.

24. Sun, L. H., Liao, J. L., Li, X. D., and Zhuo, K. 2005. Analysis of rootknot nematode species and populations based on mitochondrial DNA. Acta Phytopathol. Sin. 35:134-140.

25. Takeuchi, Y., Kanzaki, N., and Futai, K. 2005. A nested PCR-based method for detecting the pine wood nematode, Bursaphelenchus xylophilus, from pine wood. Nematology 7:775-782.

26. Thomson, D., and Henry, R. 1995. Single-step protocol for preparation of plant tissue for analysis by PCR. Biotechniques 19:394-397, 400.

27. Tigano, M., de Siqueira, K., Castagnone-Sereno, P., Mulet, K., Queiroz, P., dos Santos, M., Teixeira, C., Almeida, M., Silva, J., and Carneiro, R.
2010. Genetic diversity of the root-knot nematode Meloidogyne enterolobii and development of a SCAR marker for this guava-damaging species. Plant Pathol. 59:1054-1061.

28. Tigano, M. S., Carneiro, R. M. D. G., Jeyaprakash, A., Dickson, D. W., and Adams, B. J. 2005. Phylogeny of Meloidogyne spp. based on $18 \mathrm{~S}$ rDNA and the intergenic region of mitochondrial DNA sequences. Nematology 7:851-862.

29. Toyota, K., Shirakashi, T., Sato, E., and Wada, S. 2008. Development of a real-time PCR method for the potato-cyst nematode Globodera rostochiensis and the root-knot nematode Meloidogyne incognita. Soil Sci. Plant Nutr. 54:72-76.

30. Xu, J. H., Liu, P. L., Meng, Q. P., and Long, H. 2004. Characterization of Meloidogyne species from China using isozyme phenotypes and amplified mitochondrial DNA restriction fragment length polymorphism. Eur. J. Plant Pathol. 110:309-315.

31. Yang, B. J., and Eisenback, J. D. 1983. Meloidogyne enterolobii n. sp. (Meloidogynidae), a root-knot nematode parasitizing pacara earpod tree in China. J. Nematol. 15:381-391.

32. Yang, B. J., Wang, Q. L., Hu, K. J., Yu, S. F., Yin, Y. Q., Feng, R. Z., and $\mathrm{Wu}, \mathrm{Q} .1991$. A survey of root-knot nematodes (Meloidogyne spp.) in China. Afro-Asian J. Nematol. 1:91-93.

33. Zhuo, K., Hu, M. X., Liao, J. L., Cui, R. Q., Li, X. D., Wang, B., and Zhou, J. Y. 2008. Identification of Meloidogyne enterolobii in Guangdong Province and Hainan Province. J. Huazhong Agric. Univ. 27:193-197.

34. Zhuo, K., Hu, M. X., Liao, J. L., and Rui, K. 2010. First Report of Meloidogyne enterolobii on arrowroot in China. Plant Dis. 94:271.

35. Zijlstra, C. 1997. A fast PCR assay to identify Meloidogyne hapla, $M$ chitwoodi, and M. fallax, and to sensitively differentiate them from each other and from $M$. incognita in mixtures. Fundam. Appl. Nematol. 20:505-511.

36. Zijlstra, C., Donkers-Venne, D. T. H. M., and Fargette, M. 2000. Identification of Meloidogyne incognita, $M$. javanica and $M$. arenaria using sequence characterised amplified region (SCAR) based PCR assays. Nematology 2:847-853.

37. Zijlstra, C., Lever, A. E. M., Uenk, B. J., and Van Silfhout, C. H. 1995. Differences between ITS regions of isolates of the root-knot nematodes Meloidogyne hapla and M. chitwoodi. Phytopathology 85:1231-1237. 